\title{
Hypertension guidelines: thresholds, targets, and teratogenicity
}

The current British Hypertension Society (BHS) Guidelines for the management of Hypertension run to an impressive 46 pages. ${ }^{1}$ The Quick Reference Guide on management of hypertension in adults in primary care published by the National Institute of Health and Clinical Excellence (NICE) in June 2006 is shorter at 11 pages. ${ }^{2}$ Both documents give essentially the same message about thresholds, treatments, and targets for hypertensive patients with the NICE guide providing easy to follow, colourful flow diagrams. By definition clinical guidelines need to be clear and user-friendly but I worry that important and subtle messages may be lost completely in the process. A case in point is the management of hypertension in young women of childbearing age. In the NICE Quick Reference Guide only one line mentions this group saying that beta blockers should be avoided in women of childbearing age. There is no mention of why and no reference to the potential dangers of angiotensin converting enzyme (ACE) inhibitors or angiotensin receptor blockers (ARBs) should these women become pregnant.

Research emerging in the early 1990s indicated a causative association between the use of ACE inhibitors during pregnancy and the development of severe fetal abnormalities. A significantly increased incidence of oligohydramnios, neonatal renal failure, pulmonary hypoplasia, calvarial hypoplasia, and fetal death were reported. These effects are thought to be the result of hypoperfusion of the fetal kidneys during development. ${ }^{3}$ The increased risk of fetal abnormalities was initially thought to be limited to women receiving ACE inhibitor therapy in the second and third trimesters of pregnancy. However, a more recent study has suggested a significantly increased risk (>2.7) of major congenital malformations in women receiving ACE inhibitor therapy in the first trimester of pregnancy. ${ }^{4} \mathrm{~A}$ higher incidence of fetal abnormalities in the offspring of women taking ARBs during pregnancy has also been noted. ${ }^{5}$
Current BHS guidelines recommend ACE inhibitors as first-line agents for younger, non-black patients but advise that these agents should be avoided in women who wish to become pregnant. The recommendations also state that ACE inhibitors and ARBs should be discontinued immediately if a woman were to become pregnant while receiving treatment with either agent. The Quick Reference NICE guidelines suggest beta blockers may have a role in younger women but do not specify why. ${ }^{2}$ Despite their known adverse effects, recent US data shows that $4.4 \%$ of women of childbearing age (15-44 years) take ACE inhibitors, reflecting an $83 \%$ increase in use from 1995-2002. ${ }^{6}$ In addition, a UK poll suggests that $40 \%$ of pregnancies are unplanned, with over half of these due to lack of contraception. ${ }^{7}$

At the Hypertension Clinic, University Hospital Birmingham we recently investigated the number of women of childbearing age (16-45 years), who had been prescribed ACE inhibitors or ARBs in primary care before referral. ${ }^{8}$

In addition, contraceptive use by these women was evaluated to assess whether adequate precautions were being taken to prevent pregnancy in these at-risk patients. A cohort of female patients aged 16-45 years was identified from approximately 1500 new referrals from January 2004 to October 2006, excluding those not taking antihypertensive medication. Contraceptive status was established where possible. Forty-seven of $101(47 \%)$ women aged $16-45$ years were taking an ACE inhibitor $(n=35)$ an ARB $(n=11)$ or both $(n=1)$ of whom 26 (55\%) were aged $16-40$ years. In this younger group, eight were using no contraception and three were using barrier methods only. In other words, onequarter of women in the study were taking these agents and were aged 40 years or less; of these, many were not using reliable contraception. The study identifies a worrying trend to use ACE inhibitors or ARBs in younger women who are at risk of poor perinatal outcomes if they become pregnant.

On the basis of this small study and my own clinical experience I feel that the BHS and NICE guidelines may put younger women at risk if doctors are unaware of potential fetotoxic and teratogenic consequences of prescribing ACE inhibitors and ARBs. When I give talks to GPs and hospital doctors, several colleagues confirm that they were previously unaware of such an association. A final point that the study highlighted was the surprising number of young women who were taking antihypertensives in the first place. This brings me on to thresholds for intervention, white coat hypertension, and appropriateness of treatment in this very low-risk group: important subjects for another Viewpoint, perhaps.

\section{Una Martin}

\section{REFERENCES}

1. Williams B, Poulter NR, Brown MJ, et al. Guidelines for management of hypertension: report of the fourth working party of the British Hypertension Society, 2004-BHS IV. J Hum Hypertens 2004; 18: 139-185.

2. National Institute for Health and Clinical Excellence. Hypertension: management of hypertension in adults. in primary care. Ref CG034. London: NICE, 2006. http://www.nice.org.uk:80/nicemedia/pdf/cg034quickr efguide.pdf (accessed 4 Jul 2008).

3. Shotan A, Widerhorn J, Hurst A, Elkayam U. Risks of angiotensin-converting enzyme inhibition during pregnancy: experimental and clinical evidence, potential mechanisms, and recommendations for use. Am J Med 1994; 96: 451-456.

4. Cooper WO, Hernandez-Diaz S, Arbogast PG, et al. Major congenital malformations after first-trimester exposure to ACE inhibitors. N Engl J Med 2006; 354: 2443-2451.

5. Quan A. Fetopathy associated with exposure to angiotensin converting enzyme inhibitors and angiotensin receptor antagonists. Early Hum Dev 2006; 82: 23-28.

6. Murphy HR, Temple RC, Roland JM, et al. Improving outcomes of pregnancy for women with type 1 and type 2 diabetes. Br J Diabetes Vasc Dis 2007; 7: 38-42.

7. BBC. $40 \%$ of pregnancies 'unplanned'. London: BBC, 2006. http://news.bbc.co.uk/1/hi/health/3515400.stm (accessed 4 Jul 2008).

8. Martin U, Foreman MA, Travis JC, et al. Use of ACE inhibitors and ARBs in hypertensive women of childbearing age. J Clin Pharm Ther 2008; 33: 1-5. In press.

DOI: 10.3399/bjgp08X319800 